\title{
EU Actions to Ensure the Safety of Tattoos and the Protection of Consumers
}

\author{
Ana María Blass Rico* \\ European Commission, Justice and Consumers Directorate General Unit Product and Service Safety, \\ Brussels, Belgium
}

\begin{abstract}
The number of tattooed persons has been continuously increasing in the last few years, particularly in the younger population. At the same time, the possibility of purchasing tattoo inks online is easier than ever worldwide. Consumers are not always sufficiently aware of the possible health problems associated with this 'cool fashion' if hygiene conditions are not respected and/or if the injected mixtures contain dangerous chemicals. Concerns about the possible health risks associated with such practices arise from the absence of a clear legislative framework, the lack of proper risk assessment of the chemicals used, and non-harmonised or missing hygiene and purity requirements, among other factors. There is a general consensus among all active stakeholders that EU harmonised rules would help to ensure a consistent high level of protection of consumers across the EU.
\end{abstract}

(c) 2015 S. Karger AG, Basel

\section{Background}

In 2000, the Scientific Committee on Cosmetic Products and Non-Food Products delivered an opinion regarding the safety of tattoos. The committee recommended that a systematic effort be undertaken to amass the needed chemical and toxicological information so that a proper risk assessment could be conducted. In this light, the European Commission (EC) decided to undertake action to establish a common knowledge basis on the safety of tattoos and body piercing. The Directorate General for Health and Consumers (DG SANCO) asked the Joint Research Centre (JRC) to carry out this activity as part of the EISChemRisks project, which aimed to collect process and assess information on consumer exposure to chemicals in consumer products and articles and associated health risks. The work resulted in a report summarising the final conclusions and recommendations for regulatory action on the safety of tattoos, body piercing, and related practices in the EU [1].

In the meantime, considering that tattoos and permanent make-up (PMU) were not covered either by national legislation or by EU legislation, the Council of Europe published a resolution on

\footnotetext{
* The views expressed in this article are those of the author and cannot be considered as an official position of the European Commission.
} 
requirements and criteria for the safety of tattoos and PMU in 2003, which was superseded by a new resolution in 2008, or ResAP(2008)1 [2]. The resolution provides a recommendation on chemical and microbiological quality and on safety assessment, including a negative list of substances that should not be present in tattoos and PMU as well as the maximum allowed concentrations of a number of impurities. The recommendation provides criteria for the safety assessment of the chemicals used and encourages establishing a positive list of chemicals proven safe for this use under certain conditions.

The market surveillance authorities of several Member States have taken action (e.g. withdrawal from the market, import rejection) against tattoo inks that pose serious risks to the health and safety of consumers and have reported these inks to the EC through the Rapid Alert System for nonfood dangerous products (RAPEX) [3]. From 2010 to 2014, around 100 RAPEX notifications concerned dangerous tattoo inks, mostly due to the presence of carcinogenic and/or sensitising substances (e.g. polycyclic aromatic hydrocarbons; benzene-a-pyrene; azodyes; aromatic amines; or heavy metals such as nickel, cadmium, lead, and arsenic). ResAP(2008)1 is the benchmark for the RAPEX notifications.

It is the responsibility of the business operator to fulfil the EU legislation requirement that only safe products are put on the market. In the case of products for tattooing, this involves not only those operators supplying the tattoo ink but also the artist who is supplying the tattoo ink to the public in the course of providing the tattooing service.

Some Member States have adopted national measures that are based on $\operatorname{ResAP}(2008) 1$, prohibiting the presence of tattoo inks containing certain chemicals on the market, whilst in other measures, the general safety requirements laid down in Directive 2001/95/EC, or the General Product Safety Directive (GPSD) [4], applies. Therefore, the approaches adopted by Member
States to deal with the same risk differ. As a result, there could be problems with the free circulation of products in the EU, and furthermore, EU consumers are not equally protected. However, all EU consumers should be assured that tattoo inks are safe, irrespective of the EU country where they get the tattoo. The adoption of an EU measure is a way to ensure a consistent high level of protection of the health and safety of consumers and the proper functioning of the internal market.

With the purpose of exchanging information on the current regulatory approaches and common practices and on safety issues related to tattoos all around the world, DG SANCO organised an international virtual symposium on tattoos in April 2014. The exchange took place within the context of the International Consumer Product Safety Caucus and the Organisation for Economic Co-operation and Development. There were participants from the US, Canada, Australia, Peru, Norway and EU Member States, as well as the Organisation for Economic Co-operation and Development and the JRC of the EC at the virtual symposium. Live presentations from the EC, DG SANCO, and the US Food and Drug Administration were followed by oral contributions from various jurisdictions on their current regulatory approaches, data on inks' ingredients, market data, and statistics on undesirable effects.

In the EU, the EC invited Member States to designate national experts and identify possible stakeholders from the tattooing industry, scientists, practitioners, and others to participate in an expert working sub-group of the Consumer Safety Network. On June 23, 2014, DG SANCO organised the first meeting of the expert group on tattoos, with participants from 13 Member States (and Norway), stakeholders (tattoo ink producers, dermatologists, tattoo associations), the Council of Europe, the European Association for the Co-ordination of Consumer Representation in Standardisation (the European consumer voice in standardisation), and the JRC. 
EU Member States having national legislation based on ResAP(2008)1 explained their experience and their suggestions for improvement. The stakeholders also expressed their views, and ink producers, consumer associations, and tattoo artist associations were in favour of a legislative measure based on ResAP(2008)1 and asked for stricter rules.

\section{Tattoo Inks Must Be Safe}

The GPSD applies to tattoo inks, irrespective of whether they are purchased for self-application or by a professional tattooist and inserted under the skin of a consumer by this service provider.

The GPSD empowers the EC to adopt socalled emergency measures valid for 1 year (renewable) to address serious risks to the health and safety of consumers emanating from certain products. This is applicable when Member States differ significantly on the approach to deal with the risk, when the risk cannot be dealt with as quickly as necessary under other EU legislation applicable to the products concerned, and when the risk can be eliminated effectively only by EU measures in order to ensure a consistent high level of protection of consumers and the proper functioning of the internal market.

Based on the results of the consultation of different stakeholders and the support of Member State experts that have asked the European Commission to take actions towards EU harmonised rules for tattoos, it seems that an 'emergency' measure allowed in certain circumstances by the existing legislation governing general product safety would be generally welcomed.

The measure could incorporate parts of the recommendations in ResAP(2008)1, with some updates with regards to the negative list of chemicals. There is, however, some legal basis for limitations to what can be done through this measure. It should be noted that any such 'emergency' measure should be followed in due course by a permanent measure under existing legislative powers, either as an amendment to existing legislation or as a self-standing text.

Furthermore, the Commission is at the time of writing still assessing whether all the necessary conditions for an urgent and temporary 'emergency' EU level measure are met. This process includes gathering data about number of tattooed people in the EU, health issues associated to tattoos as well as assessment of other socioeconomic aspects that could affect stakeholders, according to the different measures that could be adopted to protect consumers from the potential hazards of tattoos.

\section{Next Steps}

With the aim of comprehensively addressing all safety issues related to tattoos and their removal, DG SANCO (as from 1 January 2015 DG JUST and CONSUMERS) has asked for the collaboration of the JRC to continue with the work of the working group of experts on tattoos as an 18-month project.

Some additional potential participants have been identified, like additional tattoo associations, experts from additional Member States and third countries (Switzerland), and the European Network of Official Cosmetics Control laboratories. Open consultations and discussions are also foreseen and will be an important part of the study.

The main goal of this project is to provide scientific and technical support to prepare future legislative actions if deemed necessary.

The JRC, with the support of the experts, will gather data on the percentage of tattooed persons in the population, the ink market, ink ingredients, health effects, toxicological aspects, removal processes, the fate of the chemicals within the human body in the long term, and regulatory review (national legislations on tattoos in and outside the EU) and will assess and update $\operatorname{ResAP(2008)1~}$ 
with regards to the list of restricted chemicals and limits as well as analytical methods, labelling requirements, safety assessment, and hygiene/ sterility requirements. Finally, the group will also look at risk perception and communication as- pects, data gaps, and research needs and lessons learnt. The project should provide conclusions on the elements to be addressed by the EU action on tattoos.

\section{References}

1 Papameletiou D, Schwela D, Zenié A, et al: Recommendations for Regulatory Action in the EU on the Safety of Tattoos, Body Piercing and of Related Practices in the EU. Ispra (VA), Italy, European Commission, Joint Research Centre (JRC), Institute for Health and Consumer Protection (IHCP), Physical and Chemical Exposure (PCE) Unit, 2003.
2 Council of Europe: Resolution ResAP (2008)1 on requirements and criteria for the safety of tattoos and permanent make-up (superseding Resolution ResAP (2003)2 on tattoos and permanent make-up). Strasbourg, France, Council of Europe, 2008.
3 European Commission: RAPEX: The rapid alert system for non-food dangerous products managed by the European Commission. http://ec.europa.eu/rapex (accessed January 1, 2015).

4 Directive 2001/95/EC of the European Parliament and of the Council of 3 December 2001 on general product safety. Official Journal of the European Communities 2002;L11:4-17. 